\title{
O PAPEL DA PERÍCIA AMBIENTAL NO CASO MARIANA/MG
}

Fernanda Silva Machado; Fábio Ferreira Morong; Célia dos Santos Silva

Universidade do Oeste Paulista - UNOESTE, Especialização em Perícia Forense, Presidente Prudente, SP. E-mail: fernanda07silvamachado@hotmail.com

\section{RESUMO}

Em 05 de novembro de 2015, a barragem do Fundão, sob gestão da empresa Samarco Mineração $\mathrm{S} / \mathrm{A}$, se rompeu carregando aproximadamente 40 milhões de metros cúbicos de rejeitos, percorrendo cerca de $600 \mathrm{~km}$ até chegar ao Oceano Atlântico. O rastro de destruição deixou prejuízos para a população e ao meio ambiente. Segundo laudo emitido pelo Instituto Brasileiro do Meio Ambiente e dos Recursos Naturais Renováveis (IBAMA) é impossível estimar o prazo para que o meio ambiente se recupere. Frente ao grande impacto ambiental, a Perícia destacou mais uma vez sua importância por meio de laudos técnicos, identificando e mensurando a intensidade dos impactos ambientais nas regiões atingidas. $O$ objetivo desse artigo é ressaltar a importância da Perícia Ambiental, baseando-se na tragédia ocorrida em Mariana/MG. Conclui-se que sem a mesma, não seria possível identificar e mensurar os impactos ambientais, o que resta evidente ser um instrumento de grande relevância à proteção ambiental.

Palavras-chave: Mariana/ MG, tragédia, perícia, meio ambiente.

\section{THE ROLE OF ENVIRONMENTAL EXPERTISE IN THE MARIANA / MG CASE}

\begin{abstract}
On November 5, 2015, the Fundão dam, under management of the company Samarco Mineração $\mathrm{S} / \mathrm{A}$, broke down carrying approximately 40 milion cubic meters tailings, traveling about $600 \mathrm{~km}$ until reaching the Atlantic Ocean.The Trail of destruction has left the population and environment. According to a report issued by the Brazilian Institute for the Environment and Renewable Natural Resources (IBAMA), it is impossible to estimate the term for environment to recover. Faced with the great environment impact, the Expertise higlighted once again its importance through technical reports, identifying and measuring the intesity of environmental impacts in the affected regions. The objetive of this article is to emphasize the importance of Environmental expertise, based on the tragedy ocurred in Mariana/ MG. It is conclued that without it, it would not to be possible to indetify and meansure environment impacts, which is clearly na instrument of great relevance to environment protection.
\end{abstract}

Keywords: Mariana / MG, disaster, expertise, environment. 


\section{INTRODUÇÃO}

Avaliado como sendo o maior desastre ambiental, o caso Mariana/MG ganhou manchetes pelo mundo todo no dia 05 de novembro de 2015, após o rompimento de uma das barragens (BRASIL. Ministério Público Federal, 2016).

Essas barragens serviam como reservatórios para os rejeitos provenientes da mineração do ferro. A barragem do Fundão, já havia apresentado diversos problemas desde a sua criação, passando por várias reformas, entretanto esses reparos não foram suficientes (BRASIL. Ministério Público Federal, 2016).

A barragem do Fundão, sob gestão da empresa Samarco Mineração S/A, se rompeu carregando aproximadamente 40 milhões de metros cúbicos de rejeitos, percorrendo cerca de $600 \mathrm{~km}$ até chegar no Oceano Atlântico (BRASL. Instituto Brasileiro Do Meio Ambiente E Dos Recursos Naturais, 2015).

O resultado desastroso e de grande impacto, ceifou a vida de 19 pessoas, aproximadamente 14 toneladas de peixes foram mortos; 240,88 hectares da Mata Atlântica foram devastados, 3 reservas indígenas foram atingidas, os estados de Minas Gerais e Espírito Santo tiverem 41 cidades prejudicadas (BRASIL. Ministério Público Federal, 2016).

Por conta do grande impacto, houve uma grande preocupação em identificar as causas, os principais responsáveis e quais medidas para remediar os danos no local, face essa preocupação o presente trabalho tem como objetivo destacar a importância da Perícia Ambiental em casos como o de Mariana/MG.

\section{METODOLOGIA}

O presente trabalho foi baseado em reflexões filosóficas, conteúdos históricos, leitura da legislação nacional, jurisprudências e doutrinas pertinentes, com abordagem hermenêuticodialética. O método aplicado é o método hipotético-dedutivo, que por meio de uma hipótese, parte, por meio da dedução, para sua comprovação ou não.

\section{RESULTADOS E DISCUSSÃO}

A Perícia Ambiental, ramo da criminalística vem se destacando no cenário brasileiro, devido parcerias entre iniciativas privadas e o Estado, que atua promovendo leis de proteção, garantindo punição para crimes contra o meio ambiente e assegurando o direito de um meio ambiente ideal, entendido como direito de todos (OLIVEIRA, et. al. 2016, p.9).

Segundo DA SILVA (2012, p. 61) “A Constituição Federal Brasileira de 1988 no capítulo dedicado ao Meio Ambiente estabelece como forma de reparação do dano ambiental três tipos de responsabilidade, a saber: civil, penal e administrativa, todas independentes e autônomas entre si".

A perícia é realizada por um profissional qualificado e o seu termo deriva do latim peritia, é considerada como um meio de provas e podem ser classificadas como vistoria, avaliação e exame (SILVEIRA, et. al., 2017). O profissional atua como um auxiliar da justiça, este pode ser oficial ou assistente técnico.

De acordo com o novo Código de Processo Civil, sem seus artigos 148 e 465 (DIDIER, BRAGA E OLIVEIRA, 2015), o juiz deve nomear um perito e fixar a data para entrega do laudo e se houver algum motivo relevante, as partes têm até 15 (quinze) dias para solicitar impedimento ou suspensão do perito, indicar um assistente técnico e apresentar quesitos.

O laudo deverá conter a exposição do objeto da perícia, análise técnica ou científica realizada pelo perito, indicação do método utilizado, desde que este seja correto e legal, resposta conclusiva a todos os quesitos apresentados pelo juiz, Ministério Público e pelas partes interessadas (BRASIL, 2015). 
Para se obter as respostas necessárias, os peritos ou assistentes técnicos podem utilizar qualquer meio necessário, entretanto as provas devem ser adquiridas de formas legais, conforme previsto na Constituição Federal (BRASIL, 2015). Para lograr êxito em resultados concretos na tutela do meio ambiente, Alves e Morong (2017) salientam a necessidade de se instituir um sistema processual moderno, inexistente até o momento. Complementam que, "adotou-se a utilização de um microssistema processual ambiental, formado pela integração da Lei da Ação Civil Pública (Lei no 7.347/1985) e do Código de Defesa do Consumidor (Lei no 8.078/1990), aplicandose subsidiariamente a estes o Código de Processo Civil.".

Como medida de garantir um trabalho de teor técnico científico, o perito não deve emitir opiniões pessoais a respeito do objeto da perícia. De acordo com o Artigo no 473, parágrafo 3으, do Código de Processo Civil de 2015 (BRASIL, 2015), o perito deve manter-se imparcial, atendo as suas designações legais.

Seguindo os parâmetros judiciais, o juiz deve apreciar o laudo e esclarecer os motivos que fizeram aceitar ou não as conclusões apresentadas, tendo como base os métodos utilizados pelo perito. Quando as informações não forem suficientes, o juiz determinará nova perícia, esta pode também ser solicitada pelas partes, e se julgada relevante, o juiz estipulará novo prazo. A nova perícia não substituíra à anterior, cabendo ao juiz determinar seus valores (BRASIL, 2015).

Na tragédia com a barragem Fundão, o inquérito policial foi instaurado pela Polícia Civil de Minas Gerais, mas devido às grandes proporções, passou a ser responsabilidade da Polícia Federal (BRASIL. Tribunal De Justiça De Minas Gerais, 2017). A equipe de peritos, formada por profissionais de várias áreas colaborou com a conclusão do laudo. Além dos peritos oficiais, o caso de Mariana/MG contou com o apoio de laudos técnicos elaborados por outros órgãos, como por exemplo, o Instituto Brasileiro do Meio Ambiente e dos Recursos Naturais Renováveis (IBAMA), CONAMA, e universidades. (BRASIL. Instituto Brasileiro Do Meio Ambiente E Dos Recursos Naturais, 2015).

A Perícia Ambiental foi responsável por avaliar o impacto causado pelo lançamento da lama com rejeitos minerais no ecossistema, problemas sócio-ambientais e crimes contra a vida, sendo determinado pelo Supremo Tribunal Federal que a Justiça Federal fique responsável pelo laudo oficial (BRASIL. Tribunal De Justiça De Minas Gerais, 2017).

A Polícia Civil de Minas Gerais ficou responsável por identificar quais os crimes ambientais e crimes contra a vida, através do inquérito policial. Atuando juntamente, a Polícia Federal ficou responsável por apresentar quais as causas e crimes ocorridos no Caso de Mariana/MG (LOPES, 2016). Os laudos oficiais elaborados pela Polícia Civil e Federal apontaram as possíveis causas para o rompimento da barragem, investigaram e indiciaram os responsáveis pela tragédia, destacando a omissão e negligência através de documentos apreendidos, que informavam sobre possíveis problemas com a barragem Fundão.

O Ministério Público de Minas Gerais e o Ministério Público Federal também instauraram inquéritos civis para identificar as causas, os crimes, a omissão dos responsáveis e as irregularidades por partes dos órgãos fiscalizadores, além de acompanhar as medidas preventivas nas barragens do Complexo Germano (LOPES, 2016).

Todos os laudos referentes à tragédia de Mariana/MG foram encaminhados para a Justiça Federal de Ponte Nova/ MG, de acordo com o Supremo Tribunal Federal (BRASIL. Tribunal De Justiça De Minas Gerais, 2017).

O Instituto Brasileiro do Meio Ambiente e de Recursos Naturais Renováveis emitiu um laudo técnico apontando seu parecer frente aos resultados da tragédia, foram analisados de forma abrangente e relevantes todos os aspectos envolvidos (BRASIL. Instituto Brasileiro Do Meio Ambiente E Dos Recursos Naturais Renováveis, 2015).

Levando em conta a qualidade da água, solo, espécies ameaçadas, Áreas de Proteção Permanente, questões sócio ambientais, o IBAMA através do Laudo Técnico Preliminar concluiu 
que "o nível de impacto foi tão profundo e perverso ao longo de diversos estratos ecológicos que é impossível estimar um prazo de retorno da fauna ao local" (BRASIL. Instituto Brasileiro do Meio Ambiente e Dos Recursos Naturais Renováveis, 2015).

A Nota Técnica no 003/2016, encaminhada pelo Centro TAMAR/ ICMBio, informou que os níveis de metais encontrados no curso do Rio Doce apresentaram como resultados, índices acima do permitido pelo CONAMA (BRASIL. Instituto Brasileiro Do Meio Ambiente e dos Recursos Naturais Renováveis, 2016).

\section{CONCLUSÃO}

A Perícia Ambiental verificou a magnitude da destruição de diversos pontos diferentes e estimou o tempo que levará para o meio ambiente se recuperar. A cada novo caso, a perícia tem se mostrado totalmente eficiente e necessária.

Após elaboração e conclusão de diversos laudos técnicos, foi possível traçar o tamanho do prejuízo causado por uma negligência humana, deixando claro que o problema não se resume apenas ao local onde houve o rompimento da barragem. O meio ambiente se recuperará lentamente, porém não há previsão para seu total reparo, frente a destruição causada.

Portanto, conclui-se que sem realização da perícia ambiental, não seria possível identificar e mensurar os impactos ambientais, o que resta evidente ser um instrumento de grande relevância à proteção ambiental.

\section{REFERÊNCIAS}

ALVES, L. N.; MORONG, F. F. A nova tutela de urgência nas ações públicas ambientais: um instrumento de efetivação da proteção ao meio ambiente. Colloquium Socialis, Presidente Prudente, v. 01, n. 1, p. 01, Jan/Abr. 2017

BRASIL. Ministério Público Federal. Caso Mariana. [2016?] Disponível em: < http://www.mpf.mp.br/para-o-cidadao/caso-mariana/o-desastre>. Acesso em: 10 ago. 2018. BRASIL. Tribunal De Justiça De Minas Gerais. Comarca de Mariana divulga balanço de ações envolvendo Samarco. 2017. Disponível em: <http://www.tjmg.jus.br/portaltjmg/noticias/comarca-de-mariana-divulga-balanco-de-acoes-envolvendosamarco.htm\#.W1D2o9JKhH0> . Acesso em: 10 ago. 2018.

BRASIL. Instituto Brasileiro Do Meio Ambiente E Dos Recursos Naturais Renováveis. Laudo Técnico Preliminar. $2015 . \quad$ Disponível em: <http://www.ibama.gov.br/phocadownload/barragemdefundao/laudos/laudo_tecnico_preliminar _lbama.pdf>. Acesso em: 10 ago. 2018.

BRASIL Instituto Brasileiro Do Meio Ambiente E Dos Recursos Naturais Renováveis. Informação Técnica no 003/2016- Centro TAMAR/ ICMBio. Vitória. 2016. Disponível em: <http://www.ibama.gov.br/phocadownload/barragemdefundao/informacoestecnicas/2016-03informacao_tecnica_03_16_ctamar_icmbio.pdf>. Acesso em 10 ago. 2018.

BRASIL. Lei $\mathrm{n}^{\circ}$ 13.105, 16 mar. 2015. Código de Processo Civil. Disponível em: <http://www.planalto.gov.br/ccivil_03/_ato2015-2018/2015/lei/l13105.htm> Acesso em: 20 jul.2018

DA SILVA, S. B. Perícia Ambiental: Definições, Danos e Crimes Ambientais. Revista UNOPAR Científica Ciências Humanas e Educação. Londrina, v. 13, n. 1, p. 61-64. 2012. 
DIDIER JUNIOR, F.; BRAGA, PAULA SARNO; OLIVEIRA, Rafael Alexandria de. Curso de Direito Processual Civil. Teoria da Prova, Direito Probatório, Decisão, Precedente, Coisa Julgada e Tutela Provisória, 10a edição, vol. 4, Salvador: Editora JusPodivm, 2015.

LOPES, L. M. N. O rompimento da barragem de Mariana e seus impactos socioambientais. 2016. Disponível em: <http://periodicos.pucminas.br/index.php/sinapsemultipla/article/view/11377>. Acesso em: 20 jul.2018.

OLIVEIRA, V. M, CALEGARI, W. A importância da Perícia Ambiental. IV Encontro Científico do Curso de Direito da Faculdade Arthur Thomas, Londrina, p. 61-64, 2015. Disponível em: <http://faatensino.com.br/encontro-cientifico-da-faculdade-arthur-thomas/>. Acesso em: 10 ago. 2018.

SILVEIRA, D; LANG, K. M. A prova pericial. Âmbito Jurídico, Rio Grande, v. XX, n. 162, jul 2017. Disponível em: $<$ http://www.ambitojuridico.com.br/site/?n_link=revista_artigos_leitura\&artigo_id=19145\&revista_caderno=21>. Acesso em: 20 jul. 2018. 